From the Association of Departments of Family Medicine

\section{FROM ADFM: AMPLIFYING ADVOCACY IN FAMILY MEDICINE}

Family physicians provided primary health care for patients, families, and communities despite great risks to themselves and their loved ones throughout the COVID-19 pandemic. Our comprehensive scope of practice provides us with unique perspectives regarding the basic conditions needed for all people to thrive such as safety, shelter, education, recreation, social support, access to healthy food, and primary health care. The pandemic or more appropriately, the syndemic, has revealed gaps and amplified health inequities within our nation and the world. ${ }^{1}$ Despite spending more money on health care than any other nation, the health of the US population lags behind most in other high-income nations. ${ }^{2-3}$

The challenge to address disparities and strive for health equity motivated the Association of Departments of Family Medicine (ADFM) to launch a new Advocacy Committee. Family Medicine (FM) advocacy encompasses actions inspired by our experiences to promote individual, health system, social, economic, educational, and/or political changes that promote human health and well-being. ${ }^{4}$ Advocacy actions can occur at the micro (clinical environment), meso (local community), or macro (national or global) policy level. ${ }^{5}$ Effective advocacy includes identifying the problem; gathering information, committing to action, collaborating with others; mobilizing resources; ${ }_{i}$ and sustaining efforts to bring about change. Family physicians are natural advocates for their patients, although many have never been trained and may not be comfortable with all levels of advocacy. The aims of the ADFM Advocacy Committee are to (1) identify opportunities for advocacy; ${ }_{i}(2)$ amplify the voice of family physicians $_{i}$ (3) support FM department advocacy efforts; and (4) identify and share advocacy resources.

For example, family physicians can promote the recent National Academies of Sciences, Engineering, and Medicine (NASEM) report that calls for widespread changes in the US health care system to support primary care as a common good. ${ }^{6}$ The report includes 5 aims:

1. Pay for primary care teams to care for people, not doctors to deliver services
2. Ensure primary care is available to every individual and community

3. Train primary care teams where people live and work

4. Design information technology that serves the patient, family, and the interprofessional care team 5. Ensure high-quality primary care is implemented throughout the United States

Family physicians can engage with local and state legislators to support the first aim. Many states have introduced legislation to increase funding for primary care, also supported by the Primary Care Collaborative (PCC). ${ }^{7}$ In some cases, legislation starts with establishing a clear definition of primary care and measuring the percentage of total medical expenditures allocated to primary care. The NASEM report recommends increasing primary care support and shifting from feefor-service to global payments.

The NASEM report calls for appropriate regulatory and legislative rules to ensure safe, ethical, and anti-racist application of new technologies, along with appropriate reimbursement to support the patient-physician relationship. Electronic health records (EHRs) have been both an ally and an albatross for practicing physicians. ${ }^{8}$ EHR implementation was designed to improve the quality of care, but the lack of interoperability has created a number of problems. ${ }^{9}$ The promise of health care portals for patients to access their own information is often thwarted by difficulties with access and navigability. AAFP has supported efforts to make IT more accessible and affordable to PCPs, protect patient privacy, and ensure standards and protocols that allow health care information to flow between physicians, payers, patients, and pharmacies. ${ }^{10}$ Other advocacy efforts have included automating prior authorizations and monitoring the impact of telehealth on access and equity. Family physicians can contribute to the development of new technologies such as artificial intelligence or advanced learning systems to strengthen primary care. ${ }^{11}$

We continue to endure a syndemic that affects us profoundly in terms of health, social connections, and economics. COVID-19 disparities, the Black Lives Matter movement, police violence, and climate change have deepened our understanding of the extreme health and social inequities that disproportionately affect disadvantaged individuals and communities. The NASEM report describing primary care as a public good emphasizes the need for family physicians to respond with coordinated and thoughtful advocacy efforts that can dramatically change investment in primary care and demonstrate our commitment to social justice and health equity. These events present a oncein-a-lifetime opportunity for fundamental changes. 
Family physicians are accountable to serve the needs of both our patients and our communities. Yet many patient's needs are not within the health sector, and few family physicians have had formal advocacy training. Fortunately, the AAFP, ${ }_{1}^{12}$ STFM $_{1}^{13}$ and others have recognized these needs and developed programs and coalitions to facilitate advocacy training and actions. We call on family physicians, departments of family medicine, and family medicine organizations to consider advocacy as a professional responsibility and to train the next generation of family physician advocates. Select an issue important to your patients and community, support and reward engagement, and join the growing ranks of family physician advocates working to strengthen primary care and promote better health for our patients, communities, and the world. Cynthia Haq, MD, Wayne Altman, MD, Elisabeth Wilson, $M D_{i}$ Tochi Iroku-Malize, MDi Reid Blackwelder, MD, Jebni Robinson, MD

Acknowledgments: Thank you to additional ADFM Advocacy Committee Members for their contributions. Jacob Prunuske, Hope Wittenberg, Michelle Roett, Steven K Rothschild, Elissa Palmer, Joseph Gravel, Allen Perkins, Jennifer Edgoose, Amanda Weidner, Sam Elwood, and Jessie Vera.

\section{References}

1. Syndemics: health in context. The Lancet. 2017;389(10072):881 10.1016/S0140-6736(17)30640-2

2. Kamal R. How does health spending in the U.S. compare to other countries? Peterson-KFF Health System Tracker. Published Jan 4, 2021. Accessed Aug 31, 2021. https://www.healthsystemtracker.org/ chart-collection/health-spending-u-s-compare-countries/\#item-start

3. Arias E, Tejada-Vera B, Ahmad F, Kochanek KD. Provisional Life Expectancy Estimates for 2020. Vital Statistics Rapid Release; no 15. National Center for Health Statistics; 2021. 10.15620/cdc:107201

4. Earnest MA, Wong SL, Federico SG. Perspective: physician advocacy: what is it and how do we do it? Acad Med. 2010;85(1):63-67.

5. Buchman S, Woollard R, Meili R, Goel R. Practicing social accountability. Can Fam Phys. 2016;62(1):15-18.

6. National Academies of Sciences, Engineering, and Medicine 2021. Implementing High-Quality Primary Care: Rebuilding the Foundation of Health Care. The National Academies Press; 2021. 10.17226/25983

7. Primary care collaborative. Published Sep 8, 2021. Accessed Sep 31, 2021. https://www.pcpcc.org/about

8. Poon EG, Trent Rosenbloom S, Zheng K. Health information technology and clinician burnout: current understanding, emerging solutions, and future directions. J Am Med Inform Assoc. 2021;28(5): 895-898. 10.1093/jamia/ocab058

9. Ayaz M, Pasha MF, Alzahrani MY, Budiarto R, Stiawan D. The Fast Health Interoperability Resources (FHIR) standard: systematic literature review of implementations, applications, challenges and opportunities. JMIR Med Inform. 2021;9(7):e21929. 10.2196/21929

10. AAFP advocacy FOCUS: Health information TECHNOLOGY (HIT). AAFP Advocacy: Health IT. Published Nov 10, 2019. Accessed Aug 17, 2021. https://www.aafp.org/advocacy/advocacy-topics/health-it. html

11. Sequeira L, Almilaji K, Strudwick G, Jankowicz D, Tajirian T. EHR "SWAT" teams: a physician engagement initiative to improve Electronic Health Record (EHR) experiences and mitigate pos- sible causes of EHR-related burnout. JAMIA Open. 2021;4(2):b018.

10.1093/jamiaopen/ooab018

12. The EveryONE Project. Published Dec 5, 2019. Accessed Sep 8, 2021. https://www.aafp.org/family-physician/patient-care/the-everyone-project.html

13. Society for the Teachers of Family Medicine. Advocacy resources and key issues. Accessed Aug 2021. https://www.stfm.org/Advocacy
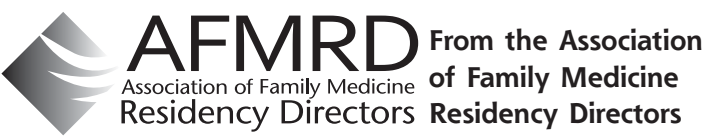
Residency Directors Residency Directors

Ann Fam Med 2021;19:570-571. https://doi.org/10.1370/afm.2751.

\section{FROM AFMRD: THE PROGRAM DIRECTOR PATIENT SAFETY AND QUALITY (PDPQ) EDUCATORS NETWORK PILOT}

In December of 2018, the AFMRD was invited by the ACGME to participate in an initiative called the Program Director Patient Safety and Quality (PDPQ) Educators Network. The PDPQ network was launched in collaboration with the Council of Medical Specialty Societies (CMSS), the Organization of Program Director Associations (OPDA), and Project ECHO. Jennifer Swoyer, DO, served as AFMRD liaison to this project.

The purpose of the PDPQ Educators Network was to design and pilot a learning network for program directors, associate program directors, and residency faculty to develop, model, and evaluate resident engagement in patient safety and health care quality improvement. Ultimately, the goal is to spread resources, lessons learned, and ideas throughout the Graduate Medical Education community.

In January 2021, 6 family medicine residency programs began the 6 -month distance learning course pilot:

Carl R. Darnall Army Medical Center, Fort Hood, Texas; Jefferson Health Northeast Family Medicine, Langhorne, Pennsylvania, La Grange Family Medicine Residency, La Grange, Illinois; Maine Dartmouth Family Medicine Residency, Augusta, Maine; and West Virginia University Rural Family Medicine, Harpers Ferry, West Viginia.

Members of 4 of the participating programs shared their experiences below.

\section{Meghan F. Raleigh, MD, FAAFP}

I was immediately drawn to the opportunity because I did not have much Quality Improvement and Patient Safety Competencies (QIPS) experience early in my training or career. 